Bài báo khoa học

\title{
Đánh giá sự thay đổi lưu lượng về hồ Dầu Tiếng theo các kịch bản biến đổi khí hậu
}

\section{Trần Tuấn Hoàng ${ }^{*}$, Phạm Ánh Bình ${ }^{1}$, Nguyễn Phương Đông ${ }^{1}$, Hồ Công Toàn ${ }^{1}$, Nguyễn Thảo Hiền ${ }^{1}$, Châu Thanh Hải ${ }^{1}$}

1 Phân viện Khoa học Khí tượng Thủy văn và Biến đổi khí hậu; hoangkttv@gmail.com; binhpi1909@gmail.com; donghai930t110@gmail.com; hocongtoanhdh@gmail.com; nthien2710@gmail.com; haisihymete@gmail.com

* Tác giả liên hệ: hoangkttv@gmail.com; Tel.: +84-903756515

Ban Biên tập nhận bài: 03/11/2020; Ngày phản biện xong: 02/12/2020; Ngày đăng bài: $25 / 12 / 2020$

Tóm tắt: Nghiên cứu ứng dụng mô hình MIKE NAM và MIKE HYDRO để mô phỏng dòng chảy đển hồ Dầu Tiếng từ đó tính toán điều tiết hồ theo các kịch bản biến đổi khí hậu $(\mathrm{BĐKH})$. Kết quả tính toán nguồn nước đến hồ cho thấy sự biến thiên rõ rệt dòng chảy theo mùa. Chênh lệch giữa năm nhiều nước và năm ít nước cũng rất đáng kể, năm nhiều nước có dòng chảy đến trung bình hơn $170 \mathrm{~m}^{3} / \mathrm{s}$ trong khi năm ít nước khoảng $36 \mathrm{~m}^{3} / \mathrm{s}$. Ngoài ra, sự thay đổi lớp phủ mặt đệm cũng là nhân tố ảnh hưởng đến chế độ dòng chảy. Mô hình MIKE HYDRO đã chứng minh tính hiệu quả vận hành thông qua trường hợp kiểm định mực nước và dung tích hồ trong 4 năm (2012-2015) và điều tiết lũ cho trận lũ lớn năm 2000. Kết quả nghiên cứu dựa vào quy trình vận hành để điều tiết hồ ứng với các trường hợp dung tích lũ nhỏ hơn mực nước dâng bình thường hay mực nước đón lũ của hồ chứa. Nghiên cứu cho thấy bộ mô hình có khả năng ứng dụng hiệu quả vào trong quản lý, quy hoạch và hỗ trợ vận hành hợp lý hồ Dầu Tiếng nhằm đảm bảo an toàn cho vùng hạ du sông Sài Gòn.

Từ khóa: Điều tiết hồ; Vận hành hồ chứa; Hồ Dầu Tiếng; Biến đổi khí hậu.

\section{Mở đầu}

Hồ chứa là một loại công trình được xây dựng để khai thác, sử dụng tổng hợp nguồn nước vào mục đích phát triển kinh tế-xã hội và phòng tránh giảm nhẹ thiên tai. Tùy vào trường hợp cụ thể, các hồ chứa thủy lợi có thể có một hoặc nhiều nhiệm vụ như: cấp nước cho nông nghiệp, công nghiệp, sinh hoạt hoặc phục vụ các ngành kinh tế khác như phát triển giao thông, phát điện, du lịch, ... Hồ chứa nước thường đem lại nguồn lợi rất lớn, là tiền đề cho sự phát triển bền vững kinh tế, xã hội và môi trường khu vực. Chính vì thế, đến nay đã có hàng triệu hồ chứa nước được xây dựng như: Hồ chứa Acyan ở Ai Cập được xây dựng vào năm 1960 với dung tích 16,2 tỷ m³ ; Hồ chứa Tam Hiệp ở Trung Quốc với dung tích hồ $38 \mathrm{~km}^{3}$, dung tích phòng lũ $22,38 \mathrm{~km}^{3}$, diện tích mặt hồ ở cao trình thiết kế là $632 \mathrm{~km}^{2}$, nhà máy thủy điện lớn nhất thế giới với công suất $22,4 \mathrm{GW}, \ldots$

Theo tiến trình phát triển hồ chứa nước, các nhà khoa học trên thế giới đã tiến hành nghiên cứu giải quyết các vấn đề liên quan đến quản lý vận hành hồ chứa đa mục tiêu với việc sử dụng nước cho nhiều mục đích khác nhau, nhằm nhằm khai thác tối đa tiềm năng của hồ, đồng thời hạn chế tới mức thấp nhất những tác động bất lợi xảy ra trong quá trình khai thác, vận hành hồ chứa. Nhiều mô hình toán dự báo lũ, mô phỏng quá trình truyền lũ từ mưa trên lưu vực đã ra đời, trong số đó mô hình mưa dòng chảy NAM (một phần của bộ mô hình MIKE của Viện Thủy lực và Môi trường Đan Mạch-DHI) đã và đang được ứng dụng nhiều 
trên thế giới [1-4]. Công tác quản lý vận hành các hồ chứa trên thế giới đã có những thành tựu lớn, cả về công cụ tính toán, thiết bị đo đạc, giám sát và hệ thống điều hành.

Hồ chứa nước ở nước ta mới được phát triển mạnh vào mấy thập niên gần đây, việc điều tiết hồ nhằm đảm bảo an toàn công trình hồ đập và hạ lưu là một công việc tiên quyết. Trong báo cáo của Ủy ban Liên Chính phủ về $B Đ K H$ (IPCC) và kịch bản Bộ Tài nguyên và Môi trường công bố năm 2016 đã có nhắc đến rằng: Việt Nam là một trong những quốc gia bị ảnh hưởng nặng nề của $\mathrm{BĐKH} \mathrm{[5-8].} \mathrm{Trong} \mathrm{những} \mathrm{năm} \mathrm{qua,} \mathrm{tác} \mathrm{động} \mathrm{của} \mathrm{BĐKH} \mathrm{có} \mathrm{thể} \mathrm{nhận}$ thấy như: mưa trái mùa, mưa cực đoan xuất hiện thường xuyên, lũ lụt, hạn hán kéo dài, nhiệt độ cao bất thường, ... đang ảnh hưởng xấu đến môi trường và công tác vận hành cũng như quản lý hồ chứa. Hàng năm, ngập ở vùng hạ du hồ Dầu Tiếng như TP. HCM, Bình Dương đã gây thiệt hại về cơ sở hạ tầng và làm giảm tốc độ phát triển của vùng kinh tế năng động nhất cả nước. Một trong những nguyên nhân gây ra ngập ở hạ du hồ Dầu Tiếng là việc xả lũ trong mùa mưa. Những năm gần đây, cùng với sự phát triển kinh tế của đất nước, nhà nước đã đầu tư nhiều cho khoa học, một số đề tài, dự án nghiên cứu về hồ chứa đã được thực hiện nhằm phát huy tối đa hiệu quả sử dụng nước, đồng thời ngăn chặn những tác động bất lợi trong quá trình quản lý vận hành, trong số đó phải kể đến những nghiên cứu có liên quan đến hồ Dầu Tiếng [9-12].

Với các nghiên cứu cho nhiều hồ chứa lớn trên thế giới đã phần nào cho thấy, khả năng ứng dụng rộng rãi bộ mô hình MIKE vào thực tế sản xuất. Trong nghiên cứu này ứng dụng mô hình MIKE NAM và MIKE HYDRO nhằm: (i) Tính toán dòng chảy đến hồ và điều tiết cho hồ Dầu Tiếng; (ii) Điều tiết hồ dựa trên các kịch bản BĐKH của Bộ Tài nguyên và Môi trường 2016 theo kịch bản RCP 4.5 và $R C P 8.5$ với hai mốc thời gian năm 2025,2030 . Với mục tiêu góp phần hiện đại hóa công tác quản lý và vận hành hệ thống hồ chứa vùng Đông Nam Bộ, từng bước đảm bảo an toàn trong phòng lũ trong điều kiện $\mathrm{BĐKH} \mathrm{ngày} \mathrm{càng} \mathrm{phức}$ tạp.

\section{Phương pháp nghiên cứu và thu thập tài liệu}

\subsection{Giới thiệu khu vục nghiên cứu}

Hồ Dầu Tiếng được xây dựng ở thượng lưu sông Sài Gòn, tại ngã ba Dầu Tiếng, huyện Dầu Tiếng, tỉnh Bình Dương, trải dài từ $11^{\circ} 12^{\prime}$ tới $12^{\circ} 00^{\prime}$ vĩ độ Bắc và từ $106^{\circ} 10^{\prime}$ đến 106³0' kinh độ Đông, cách TP. HCM khoảng trên $100 \mathrm{~km}$ theo đường liên tỉnh. Hồ Dầu Tiếng là một trong những hồ chứa lớn nhất Việt Nam, có toàn bộ diện tích mặt nước là 27.000 hecta, sức chứa 1580 triệu $\mathrm{m}^{3}$, trong đó dung tích hữu ích là 1110 triệu $\mathrm{m}^{3}$. Hồ Dầu Tiếng có nhiệm vụ điều tiết lũ và kiểm soát mặn ở hạ lưu, dự trữ nước ngọt và cấp nước tưới cho các tỉnh Tây Ninh, Bình Dương, Bình Phước và TP. HCM.

Trong những năm gần đây, tình hình thời tiết diễn biến khó lường thì những trận mưa lớn trên $100 \mathrm{~mm}$ xuất hiện nhiều hơn, mưa lớn kết hợp với triều cường trên sông Sài Gòn cộng với xả lũ ở các hồ thượng nguồn đã gây ra ngập úng không chỉ khu vực TP. HCM mà còn nhiều khu vực ven sông Sài Gòn thuộc tỉnh Bình Dương gây thiệt hại to lớn về cơ sở hạ tầng, sản xuất nông nghiệp và làm giảm tốc độ phát triển kinh tế vùng. Để giảm thiểu lũ lụt cho vùng hạ $\mathrm{du}$, nhiều giải pháp đã được nghiên cứu, đề xuất như nạo vét kênh phân lũ qua sông Vàm Cỏ Đông, làm hồ điều hòa để chậm lũ, đắp đê, nâng cao đập,... Tuy nhiên, các giải pháp phi công trình còn ít được nghiên cứu. Thêm vào đó, chế độ thủy văn của hồ đã có sự thay đồi do diện tích rừng đầu nguồn giảm, sự phát triển của cơ sở hạ tầng, chuyển đất canh tác cũng đã tác động mạnh mẽ đến việc vận hành và quản lý hồ nhất là trong mùa lũ. 


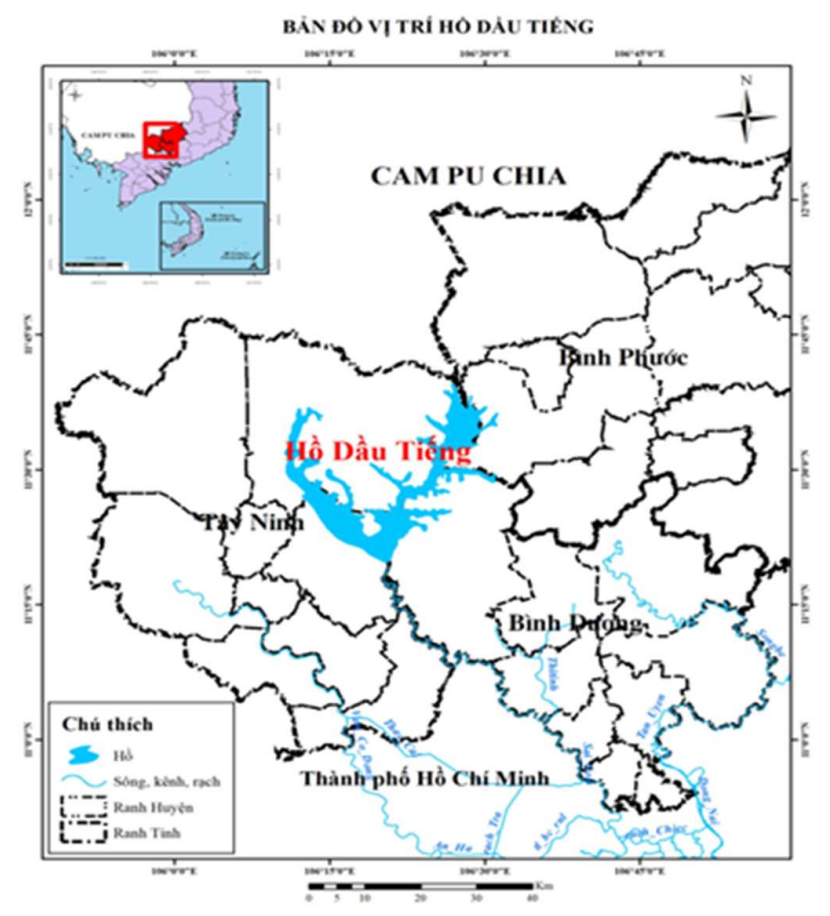

Hình 1. Bản đồ vị trí lưu vực hồ Dầu Tiếng.

\subsection{Mô hìh MIKE NAM, MIKE HYDRO Basin}

\subsubsection{Mô hình thủy văn MIKE NAM}

Mô hình NAM là mô hình cải tiến từ mô hình Nielsen-Hansen, được công bố trong tạp chí "Nordic Hydrology" năm 1973, sau này được DHI phát triển và đổi thành NAM (Nedbor-Afstromnings Model). Cấu trúc mô hình NAM được xây dựng trên nguyên tắc các hồ chứa theo chiều thẳng đứng và các hồ chứa tuyến tính, gồm có 4 bể chứa theo chiều thẳng đứng [13]. Trong đó mỗi bể chứa đặc trưng cho một môi trường có chứa các yếu tố gây ảnh hưởng đến quá trình hình thành dòng chảy trên lưu vực. Các bể chứa được liên kết với nhau bằng các biểu thức toán học. Qua đó sự hình thành dòng chảy trên lưu vực được mô tả gần giống với hiện tượng thực tế. Các bể chứa đó gồm: Bể tuyết (chỉ áp dụng cho vùng có tuyết), bể mặt, bể sát mặt hay bể tầng rễ cây và bể ngầm. Mô hình NAM thuộc loại mô hình tất định, thông số tập trung, và là mô hình mô phỏng liên tục. Trong nghiên cứu này, mô hình NAM được ứng dụng để tính toán dòng chảy đến hồ chứa. Dữ liệu đầu vào của mô hình là mưa, bốc hơi tiềm năng và nhiệt độ. Úng với các kịch bản $\mathrm{BĐKH}$, thay đổi nhiệt độ và lượng mưa sẽ ảnh hưởng tới dòng chảy đến hồ chứa thượng lưu khu vực nghiên cứu.

\subsubsection{Mô hình thủy văn lưu vực MIKE HYDRO BASIN}

Mô hình MIKE HYDRO Basin [14] là một công cụ cân bằng giữa nhu cầu về nước và nước có sẵn theo cách tối ưu nhất giúp cho công tác điều tiết hệ thống thủy lợi, quy hoạch lưu vực sông tổng hợp và quản lý tài nguyên nước do DHI xây dựng, đây là một mô hình toán học thể hiện một lưu vực sông bao gồm cấu hình của các sông chính và các sông nhánh, các yếu tố thủy văn của lưu vực theo không gian và theo thời gian, các công trình, hệ thống sử dụng nước hiện tại và tương lai và các phương án sử dụng nước khác nhau. MIKE HYDRO Basin được xây dựng theo kiểu mô hình mạng lưới, trong đó sông và các nhánh hợp lưu chính được biểu diễn bằng một mạng lưới bao gồm các nhánh và các nút. Nguyên lý tính toán điều tiết 
dòng chảy trong hồ chứa dựa vào hệ phương trình cân bằng nước cùng với các đường đặc trưng, tham số mô tả đặc tính của hệ thống công trình [15].

- Phương trình cân bằng nước:

$$
\frac{d V}{d t}=Q(t)-q_{r}(t)
$$

Trong đó $\mathrm{Q}(\mathrm{t})$ là lượng nước đến hồ theo thời gian $\left(\mathrm{m}^{3} / \mathrm{s}\right) ; \mathrm{qr}(\mathrm{t})$ là lượng nước ra khỏi hồ là lưu lượng xả qr $(\mathrm{t})$ qua công trình $\left(\mathrm{m}^{3} / \mathrm{s}\right) ; \mathrm{dV} / \mathrm{dt}$ thay đổi lượng nước trong hồ theo thời gian $\left(\mathrm{m}^{3}\right)$. Giải hệ phương trình trên xác định được đường quá trình lưu lượng xả $\mathrm{qx}(\mathrm{t})$ sự thay đổi mực nước và dung tích của hồ chứa.

MIKE HYDRO Basin bao gồm các môđun: mưa-dòng chảy (NAM), mạng lưới hồ chứa (Reservoir Network) và mô phỏng (Simulation). Các nút được thiết lập trong mô hình gồm: Nút đơn (Simple node), nút lưu vực (Catchment node), nút hồ chứa (Reservoir) và nút nhu cầu nước (Water user definitions).

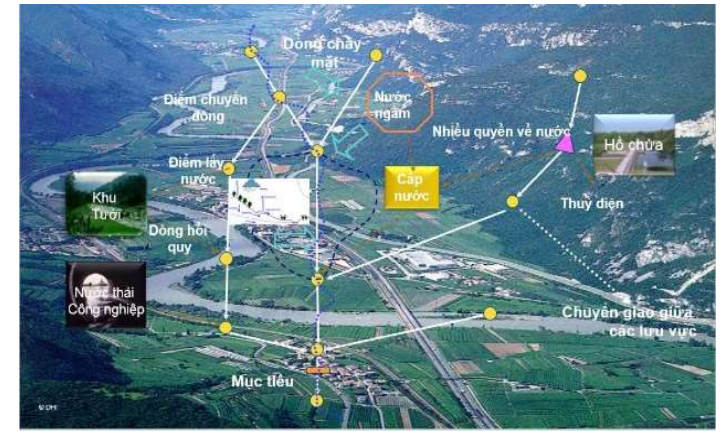

Hình 2. Sơ đồ tổng quát các môđun của mô hình MIKE HYDRO BASIN.

\subsection{Phưong pháp nghiên cứu và thiết lập mô hình}

\subsubsection{Phương pháp xây dựng kịch bản biến đổi khí hậu cho khu vực hồ Dầu Tiếng}

Phương pháp chi tiết hóa động lực được sử dụng để xây dựng kịch bản BĐKH độ phân giải cao cho lưu vực Hồ Dầu Tiếng gồm kịch bản trung bình RCP4.5 và kịch bản cao RCP8.5. Bốn mô hình khí hậu khu vực được áp dụng bao gồm: CCAM, RegCM, PRECIS và clWRF. Mỗi mô hình có các phương án tính toán khác nhau dựa trên kết quả tính toán từ các mô hình toàn cầu của IPCC [8].

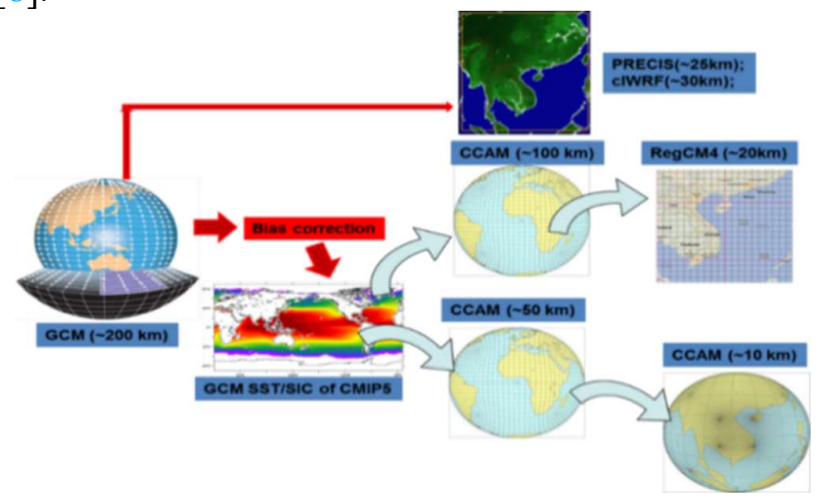

Hình 3. Sơ đồ mô tả quá trình chi tiết hóa động lực độ phân giải cao [8].

Trong kịch bản BĐKH cho Việt Nam sử dụng: Sự thay đổi của nhiệt độ và mưa được so sánh với thời kỳ cơ sở 1986-2005, đây cũng là giai đoạn được IPCC dùng trong báo cáo lần thứ năm [6-8].

Đối với nhiệt độ:

$$
\Delta T_{\text {future }}=T^{*} \text { future }-\overline{T_{1986-2005}^{*}}
$$


Đối với lượng mưa:

$$
\Delta R_{\text {future }}=\frac{\left(R_{\text {future }}-\overline{R_{1986-2005}^{*}}\right)}{\overline{R_{1986-2005}^{*}}} * 100
$$

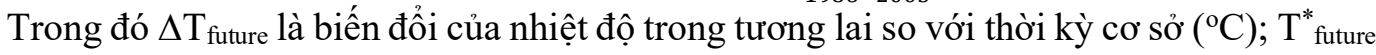
là nhiệt độ tương lai $\left({ }^{\circ} \mathrm{C}\right) ; \mathrm{T}^{*}{ }_{1986-2005}$ là nhiệt độ trung bình của thời kỳ cơ sở $\left({ }^{\circ} \mathrm{C}\right) ; \Delta \mathrm{R}_{\text {future là }}$

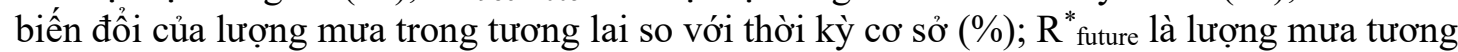
lai (mm); ${ }^{*}{ }_{1986-2005}$ là lượng mưa trung bình của thời kỳ cơ sở (mm).

Mô hình khí hậu động lực có ưu điểm là mô phỏng tốt các quá trình vật lý và hóa học trong khí quyển, tuy nhiên khó phản ánh được các yếu tố địa phương và mô hình đều tồn tại sai số hệ thống nhất định. Để khắc phục điều này, phương pháp thống kê (hiệu chỉnh phân vịQuantile Mapping) được áp dụng để hiệu chỉnh kết của mô hình theo số liệu thực đo tại trạm quan trắc [12, 16-17].

Qua phân tích và đánh giá sai số kế thừa từ kịch bản $\mathrm{BĐKH} \mathrm{và} \mathrm{NBD} \mathrm{năm} 2016$ [8]: đã chọn được tổng cộng 12 phương án tính toán tốt nhất của bốn mô hình để xây dựng kịch bản BĐKH chi tiết cho khu vực nghiên cứu. Trong đó, đối với nhiệt độ là lựa chọn 08 phương án của ba mô hình ( 04 phương án CCAM, 03 phương án PRECIS và 01 phương án clWRF); đối với lượng mưa là lựa chọn 03 phương án của mô hình PRECIS [8]. Đánh giá kết quả của 4 mô hình khí hậu được áp dụng ở Việt Nam cho thấy, các mô hình đều mô phỏng khá tốt nhiệt độ trên hầu hết các khu vực của Việt Nam, chỉ riêng mô hình clWRF có sai số hệ thống tương đối lớn. Kết quả tính toán về lượng mưa có sự khác biệt giữa các mô hình đối với các vùng khí hậu của Việt Nam. Trong đó, mô hình PRECIS cho kết quả tính toán tốt hơn so với các mô hình còn lại [19]. Để đảm bảo mức độ tin cậy, kịch bản biến đổi khí hậu đối với nhiệt độ được xây dựng theo kết quả tính toán của cả 3 mô hình với 8 phương án, kịch bản biến đổi của lượng mưa được xây dựng dựa trên kết quả tính toán từ 3 phương án của mô hình PRECIS.

\subsubsection{Thiết lập mô hình thủy văn}

Các số liệu dòng chảy đến được tính toán từ mô hình NAM. Thu thập tài liệu, số liệu khí tượng thủy văn từ các trạm khoảng 10 năm (từ năm 2007-2016) với dạng số liệu trung bình ngày.

- Số liệu khí tượng: Sử dụng 6 trạm đo mưa thuộc khu vực nghiên cứu: Lộc Ninh, Đồng Ban, Katum, Chơn Thành, Phước Long và Đồng Xoài.

- Số liệu nhiệt độ, bốc hơi trạm Tây Ninh, Đồng Xoài, Phước Long.

- Số liệu thủy văn: lưu lượng về hồ và lưu lượng xả hồ Dầu Tiếng.

- Sử dụng bản đồ số độ cao (Digital Elavation Model-DEM).

\section{a. Phân chia lưu vục}
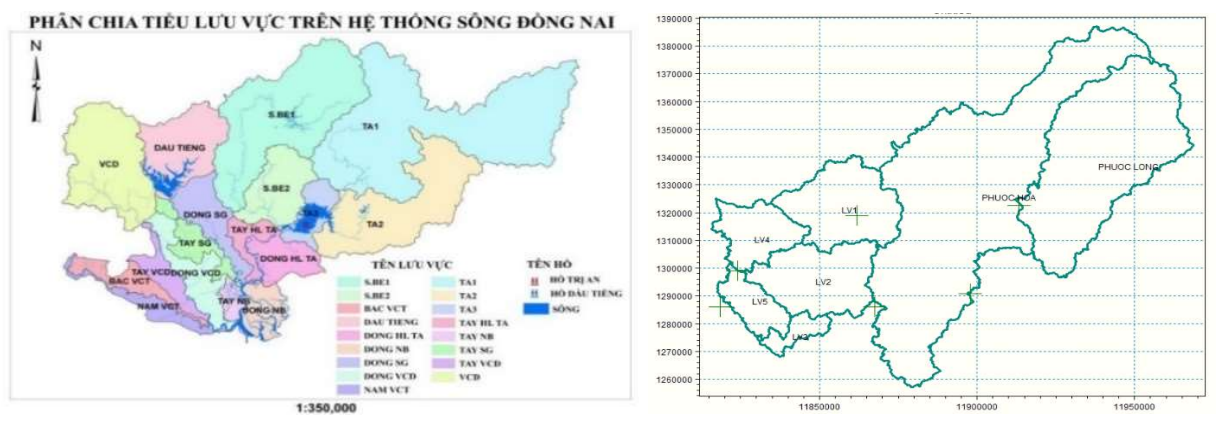

Hình 4. Phân chia lưu vực tính toán.

Các lưu vực được xác định ranh giới trên cơ sở dữ liệu bản đồ số độ cao DEM với độ phân giải $30 \mathrm{~m}$ x $30 \mathrm{~m}$ và sử dụng các Tool trong Arcgis để phân chia lưu vực dưới dạng shapefile tiểu lưu vực. Diện tích các lưu vực trình bày trong Bảng 1 . 
Bảng 1. Diện tích các tiểu lưu vực khu vực nghiên cứu.

\begin{tabular}{cclrc}
\hline STT & Tên lưu vực & Tiểu lưu vực & Diện tích $\left.\mathbf{( k m}^{\mathbf{2}}\right)$ & Tổng diện tích $\mathbf{( k m}^{\mathbf{2}} \mathbf{~}$ \\
\hline \multirow{2}{*}{ Lưu vực hồ Dầu Tiếng } & LV1 & 884,663 & 2644,25 \\
& & LV2 & 829,276 & \\
& & LV3 & 155,259 & \\
& & LV4 & 305,296 & \\
\multirow{2}{*}{2} & \multirow{2}{*}{ Lưu vực sông Bé } & LV5 & 469,752 & \\
& & Phuoc Long & 3987,06 & 6273,77 \\
& & Phuoc Hoa & 2286,71 & \\
\hline
\end{tabular}

Kết quả phân chia lưu vực vùng nghiên cứu được thể hiện lần lượt ở hình 4 cho thấy lưu vực hồ Dầu Tiếng và lưu vực sông Bé phù hợp với thực tế lưu vực hứng nước.

\section{b. Tính trọng số mura}

Để tính toán trọng số mưa bằng phương pháp đa giác Thiessen, cần có dữ liệu phân định tiểu lưu vực và dữ liệu mưa (6 trạm đo mưa). Cơ sở của phương pháp là coi lượng mưa đo được ở một vị trí nào đó trên lưu vực chỉ đại diện cho lượng mưa của một khu vực nhất định quanh nó. Diện tích của khu vực đó được khống chế bởi các đường trung trực của các đoạn thẳng nối liền các trạm với nhau và đường phân lưu (Bảng 2).

Tiến hành hiệu chỉnh mô hình bằng phương pháp thử sai nhiều lần, sử dụng các chỉ tiêu để đánh giá độ tin cậy của bộ thông số. Bộ thông số sau khi hiệu chỉnh trong mô hình NAM sẽ được sử dụng để tính toán biên cho mô hình thủy văn lưu vực.

Bảng 2. Trọng số mưa theo phương pháp Thiessen cho các TLV.

\begin{tabular}{cccccccc}
\hline \multirow{2}{*}{ STT } & \multirow{2}{*}{ Lưu vục } & \multicolumn{5}{c}{ Trọng số trạm mưa } \\
\cline { 3 - 7 } & & Lộc Ninh & Chơn Thành & Katum & Đồng Ban & Phước Long & Đồng Xoài \\
\hline 1 & LV1 & 1 & & & & & \\
2 & LV2 & 0,199 & 0,437 & 0,36 & 0,00382 & \\
3 & LV3 & & 0,488 & & 0,512 & & \\
4 & LV4 & 0,0913 & & 0,909 & & & \\
5 & LV5 & & & 0,314 & 0,686 & & \\
6 & Phuoc Long & & & & & 0,972 & 0,0284 \\
7 & Phuoc Hoa & 0,115 & 0,205 & & & 0,52 & 0,15 \\
\hline
\end{tabular}

- Thời gian tính toán: năm 2016 để hiệu chỉnh mô hình và kiểm định mô hình trong 3 giai đoạn: giai đoạn 1 từ 2011-2015, giai đoạn 2 từ 2007-2010 và năm lũ (năm 2000).

- Bước thời gian tính $\Delta \mathrm{t}=1$ ngày.

- Sử dụng lưu lượng về hồ Dầu Tiếng để hiệu chỉnh kiểm định mô hình.

\subsubsection{Thiết lập mô hình điều tiết hồ}

Từ bộ thông số mô hình NAM đã hiệu chỉnh và kiểm định, tính toán phân bố dòng chảy đến hồ chứa theo năm điển hình trung bình nước, nhiều nước $(25 \%)$, ít nước $(75 \%, 85 \%)$, xuất kết quả mưa, bốc hơi, lưu lượng về làm dữ liệu đầu vào cho mô hình MIKE HYDRO Basin.

a. Phân chia lư vục

Kết quả phân chia các tiểu lưu vực trong mô hình MIKE NAM được liên kết vào mô hình MIKE HYDRO nhằm thiết lập lưu vực và mạng lưới tính toán trong mô hình MIKE HYDRO 


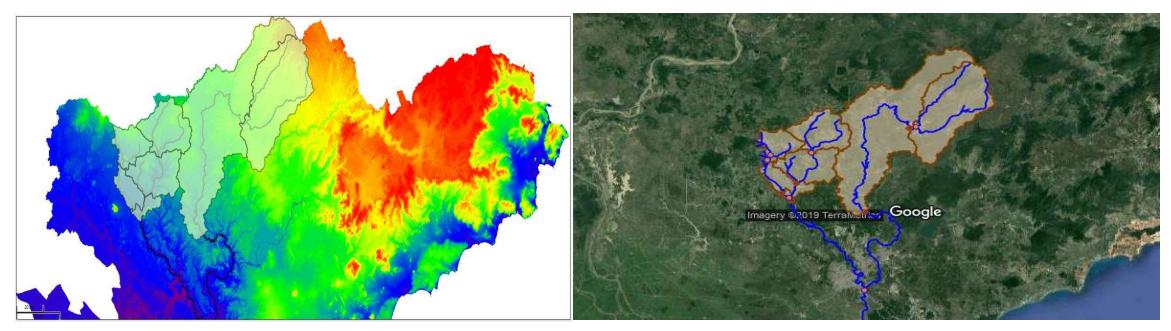

Hình 5. Phân chia lưu vực tính toán trong MIKEHYDRO BASIN.

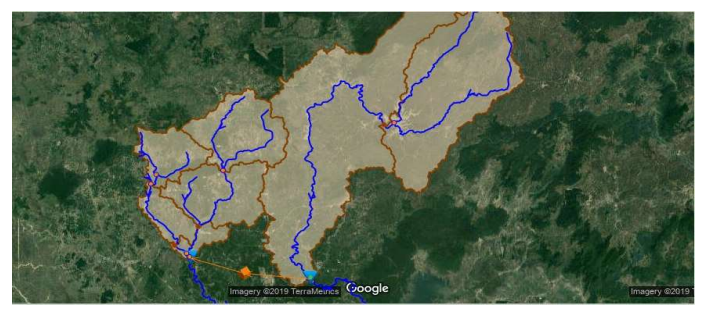

Hình 6. Thiết lập lưu vực và mạng lưới hồ trong mô hình.

Mạng lưới tính toán thể hiện ở Hình 6 bao gồm: 8 nhánh sông, 17 nút tính toán và 7 tiểu lưu vực. Có 2 nút hồ là hồ Dầu Tiếng và hồ Phước Hòa và 1 nút nhu cầu nước (nhằm tính toán điều tiết hồ Dầu Tiếng khi có bổ sung nước từ hồ Phước Hòa).

Dữ liệu cần thu thập liên quan đến hồ chứa: lưu lượng xả qua cửa và các cống, các thông số cơ bản của hồ chứa, quy trình vận hành hồ, đường phòng phá hoại, đường hạn chế cấp nước, các quan hệ đặc tính lòng hồ, ...

- Điều kiện ban đầu và dữ liệu biên: Điều kiện ban đầu bao gồm các thông số cơ bản của mô hình (mực nước chết của hồ $\mathrm{Z}_{\mathrm{c}}=17 \mathrm{~m}, \mathrm{MNDBT} \mathrm{H}_{\mathrm{bt}}=24,4 \mathrm{~m}$, mực nước lũ thiết kế 25,1 $\mathrm{m})$.

- Hiệu chỉnh, kiểm định mô hình: Kiểm tra mực nước hồ và dung tích hồ từ năm 2012 đến năm 2015 sau đó dùng năm lũ đặc biệt lớn (năm 2000) để kiểm định mô hình nhằm xem xét khả năng mô phỏng vận hành xả theo thực tế của hồ.

\section{b. Xét bài toán điều tiết lũ cho hồ Dầu tiếng theo quy trình vận hành hồ}

Các trường hợp điều tiết: Dòng chảy đến hồ Dầu Tiếng sau khi có bổ sung từ hồ Phước Hòa là $50 \mathrm{~m} / \mathrm{s}$ liên tục và không thay đổi theo quyết định của Bộ Nông nghiệp và Phát triển nông thôn [20]. Chọn tính toán cho trường hợp năm trung bình nước làm năm hiện trạng để thiên về cấp nước an toàn. Đây cũng là trường hợp dễ xảy ra nhất. Dựa theo quy trình vận hành hồ, tiến hành điều tiết hồ Dầu Tiếng theo hai cao trình mực nước đón lũ khác nhau:

- Trường hợp 1: Cao trình mực nước hồ $\mathrm{Z}_{\mathrm{hồ}}=+23,30 \mathrm{~m}$ xuất hiện lũ chính vụ (tháng 9 , tháng 10$)$, tiến hành xả từ cao trình $+23,30 \mathrm{~m}$ theo hiện trạng và các kịch bản $\mathrm{BĐKH}$;

- Trường hợp 2: Điều tiết để mực nước cao nhất trong hồ không vượt quá cao trình mực nước dâng bình thường $(+24,40 \mathrm{~m})$, theo hiện trạng và kịch bản $\mathrm{BĐKH}$.

Hồ trữ lượng nước đến trong mùa lũ để dùng cho mùa kiệt, dung tích hồ giới hạn bởi mực nước chết $(\mathrm{Hc}=17,0 \mathrm{~m})$ và mực nước dâng bình thường $\left(\mathrm{H}_{\mathrm{bt}}=24,4 \mathrm{~m}\right)$. Thời điểm bắt đầu tính toán vào ngày 01 tháng 7 hàng năm (thời điểm bắt đầu mùa mưa) trong trường hợp có bổ sung nước liên tục từ hồ Phước Hòa.

\subsubsection{Chỉ tiêu đánh giá}

Các thông số trong mô hình sẽ được xác định bằng cách tính toán và thử sai. Sử dụng hệ số Nash-Sutcliffe để đánh giá sai số giữa số liệu mô phỏng và thực đo.

Hệ số Nash-Sutcliffe (NSE): 


$$
N S E=1-\frac{\sum_{i=1}^{N}\left(Q_{o b s, i}-Q_{s i m, i}\right)^{2}}{\sum_{i=1}^{N}\left(Q_{o b s, i}-\bar{Q}_{o b s}\right)^{2}}
$$

Trong đó $\mathrm{Q}_{\text {sim,i }}$ là lưu lượng mô phỏng tại thời gian $\mathrm{i}$; $\mathrm{Q}_{\mathrm{obs}, \mathrm{i}}$ là lưu lượng thực đo tại thời gian $\mathrm{i} ; \bar{Q}_{\text {obs }}$ là lưu lượng trung bình thực đo.

Bảng 3 thể hiên tiêu chuẩn đánh giá hệ số NSE theo WMO (World Meteorological Organization).

Bảng 3. Tiêu chuẩn đánh giá hệ số NSE.

\begin{tabular}{cccc}
\hline NSE & $\mathbf{0 , 4 - 0 , 6 5}$ & $\mathbf{0 , 6 5}-\mathbf{0 , 8 5}$ & $\mathbf{> 0 , 8 5}$ \\
\hline Đánh giá & Đạt & Khá & Tốt \\
\hline
\end{tabular}

\section{Kết quả và thảo luận}

\subsection{Kịch bản biến đổi khi hậu tại hồ Dầu Tiếng}

Kịch bản tổ hợp theo các phương án tổ hợp của kịch bản quốc gia sau khi đã hiệu chỉnh thống kê các mô hình khí hậu cho biến đổi của lượng mưa và nhiệt độ tại khu vực Hồ Dầu Tiếng. Hai kịch bản RCP 4.5 và RCP 8.5 được xây dựng theo 3 giai đoạn: đầu thế kỷ 21 (2016-2035), giữa thế kỷ 21 (2045-2065) và cuối thế kỷ 21 (2080-2099) so với thời kỳ cơ sở (1986-2005).

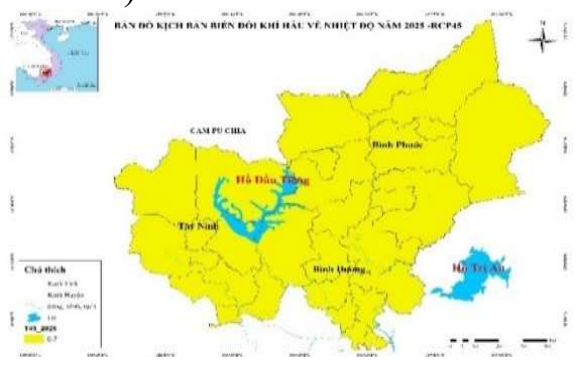

a) Kịch bản nhiệt độ năm 2025 RCP4.5

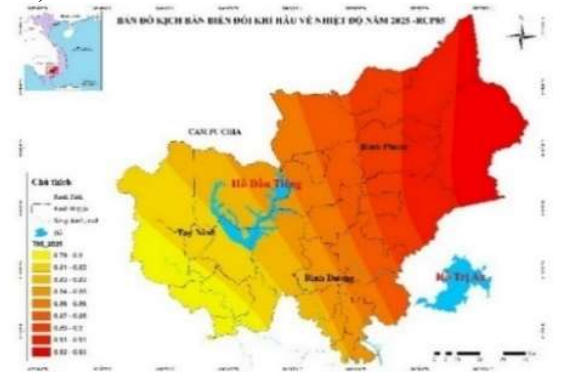

c) Kịch bản nhiệt độ năm 2025 RCP8.5

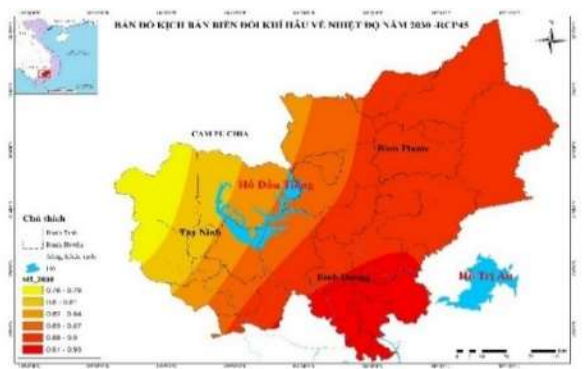

b) Kịch bản nhiệt độ năm 2030 RCP4.5

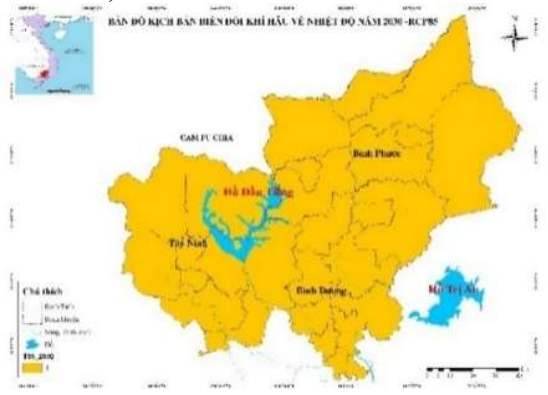

d) Kịch bản nhiệt độ năm 2030 RCP8.5

Hình 7. Mức biến đổi nhiệt độ trung bình $\left({ }^{\circ} \mathrm{C}\right)$ theo kịch bản $\mathrm{RCP} 4.5$ và RCP 8.5.

Theo kịch bản RCP8.5 (Hình 7c), vào năm 2025, nhiệt độ trung bình mùa khô tăng 0,8 $0,9^{\circ} \mathrm{C}$, mức tăng tại Sở Sao và Tây Ninh là $0,8^{\circ} \mathrm{C}$ và tăng cao hơn ở Đồng Xoài, Phước Long tăng $0,9^{\circ} \mathrm{C}$. Đến năm 2030 (Hình $7 \mathrm{~d}$ ), nhiệt độ trung bình tại khu vực Hồ Dầu Tiếng có xu thế tăng với mức tăng $1^{\circ} \mathrm{C}$ ở cả 4 trạm Đồng Xoài, Phước Long, Sở Sao, Tây Ninh. Mức biển đổi nhiệt độ ở kịch bản RCP8.5 đều cao hơn so với ở kịch bản RCP4.5 với hai mốc thời gian năm 2025 và 2030. 


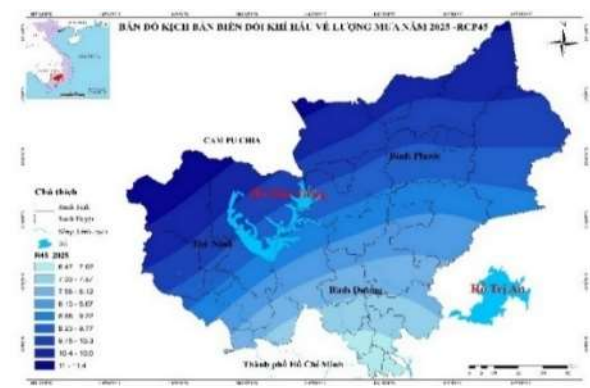

a) Kịch bản lượng mưa năm 2025 RCP4.5

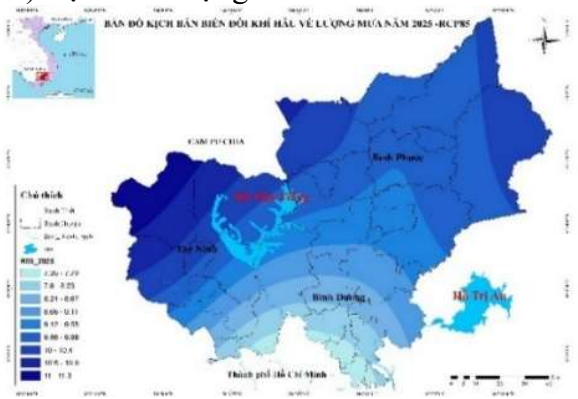

c) Kịch bản lượng mưa năm 2025 RCP8.5

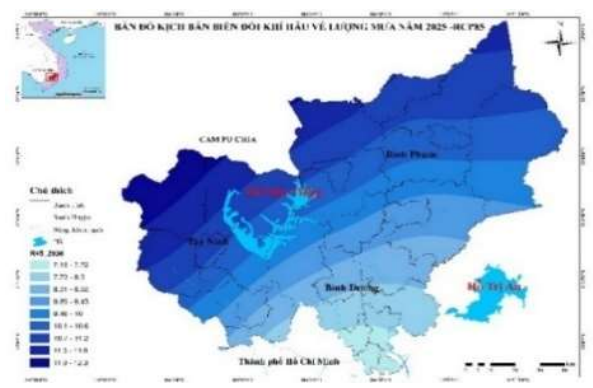

b) Kịch bản lượng mưa năm 2030 RCP8.5

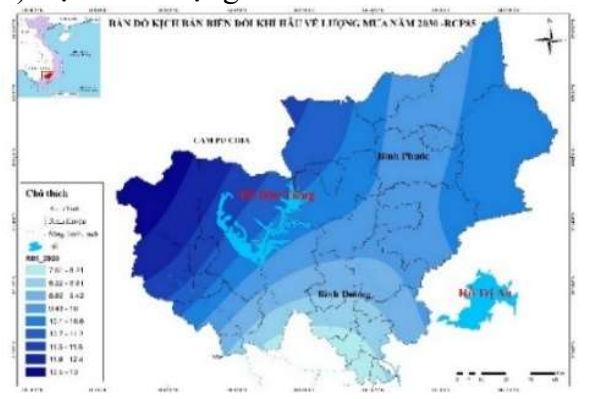

d) Kịch bản lượng mưa năm 2030 RCP8.5

Hình 8. Mức biến đổi lượng mưa trung bình (\%) theo kịch bản RCP4.5 và RCP 8.5.

Theo kịch bản RCP8.5, mức biến đổi lượng mưa năm 2025 (Hình 8c) tăng 10,1\% ở trạm Tây Ninh; tăng 7,6\% ở trạm Sở Sao, 9,6\% ở trạm Đồng Xoài, Phước Long tăng 9,7\%. Đến năm 2030 (Hình 8d), lượng mưa tăng lên so với năm 2025 cụ thể tại Tây Ninh tăng 11,5\%, Sở Sao tăng $8,1 \%$, Đồng Xoài tăng $10 \%$ và Phước Long tăng $9,9 \%$, phân bố mức độ biến đổi tăng dần theo hướng Đông Nam lên Tây Bắc.

Bảng 5. Mức biến đổi nhiệt độ trung bình và lượng mưa mùa khô, mùa mưa so với thời kỳ 19862005 theo kịch bản RCP4.5 và RCP8.5.

\begin{tabular}{|c|c|c|c|c|c|c|c|c|}
\hline \multirow{3}{*}{ STT } & \multirow{3}{*}{ Kịch bản } & \multirow{3}{*}{ Mùa } & \multicolumn{6}{|c|}{ Tên trạm } \\
\hline & & & \multicolumn{2}{|c|}{ Đồng Xoài } & \multicolumn{2}{|c|}{ Phước Long } & \multicolumn{2}{|c|}{ Tây Ninh } \\
\hline & & & $\begin{array}{c}\text { Mura } \\
(\%)\end{array}$ & $\begin{array}{c}\text { Nhiệt độ } \\
\left({ }^{\circ} \mathrm{C}\right)\end{array}$ & $\begin{array}{c}\text { Mura } \\
(\%) \\
\end{array}$ & $\begin{array}{c}\text { Nhiệt độ } \\
\left({ }^{\circ} \mathrm{C}\right)\end{array}$ & $\begin{array}{c}\text { Mưa } \\
(\%)\end{array}$ & $\begin{array}{c}\text { Nhiệt dộ } \\
\left({ }^{\circ} \mathrm{C}\right)\end{array}$ \\
\hline 1 & RCP4.5 năm & Mưa & 9,8 & 0,7 & 9,1 & 0,7 & 8,0 & 0,6 \\
\hline 2 & 2025 & Khô & 3,3 & 0,8 & 16,9 & 0,8 & 20,0 & 0,7 \\
\hline 3 & RCP4.5 năm & Mưa & 11,2 & 0,8 & 10,2 & 0,8 & 9,6 & 0,8 \\
\hline 4 & 2030 & Khô & 1,3 & 0,9 & 19,7 & 0,9 & 18,4 & 0,9 \\
\hline 5 & RCP8.5 năm & Mưa & 11,8 & 0,8 & 11,0 & 0,8 & 10,1 & 0,8 \\
\hline 6 & 2025 & Khô & $-2,1$ & 0,9 & 1,4 & 0,9 & 11,5 & 0,8 \\
\hline 7 & RCP8.5 năm & Mưa & 13 & 1,0 & 11,7 & 1,0 & 11,5 & 1,0 \\
\hline 8 & 2030 & Khô & $-6,2$ & 1,0 & $-2,3$ & 1,0 & 13,2 & 1,0 \\
\hline
\end{tabular}

3.2 Úng dụng mô hình thủy văn để tính toán lư lương về hồ

Mục đích ứng dụng mô hình thủy văn MIKE NAM nhằm xác định lưu lượng thượng nguồn (lưu lượng về hồ Dầu Tiếng) tương ứng với các kịch bản mưa. Kết quả hiệu chỉnh, kiểm định mô hình như sau:

Hiệu chỉnh mô hình: Chọn năm 2016 để hiệu chỉnh mô hình bằng phương pháp thử sai để có bộ thông số mô hình. 
Bảng 6. Các thông số mô hình NAM đã hiệu chỉnh tại lưu vực hồ Dầu Tiếng.

\begin{tabular}{llc}
\hline \multicolumn{1}{c}{ Ký hiệu } & \multicolumn{1}{c}{ Thông số mô hình hồ Dầu Tiếng } & Giá trị \\
\hline $\mathrm{U}_{\max }(\mathrm{mm})$ & Hàm lượng nước tối đa trữ trong bề mặt & 23,6 \\
$\mathrm{~L}_{\max }(\mathrm{mm})$ & Lượng nước tối đa tầng rễ cây & 350 \\
CQOF & Hệ số dòng chảy tràn & 0,45 \\
CKIF $(\mathrm{tg})$ & Hằng số thời gian dòng chảy sát mặt & 201 \\
$\mathrm{CK} 1,2$ & Hằng số thời gian dòng chảy mặt và sát mặt & 27,5 \\
TOF & Giá trị ngưỡng dòng chảy mặt & 0,01 \\
TIF & Giá trị ngưỡng dòng chảy sát mặt & 0,01 \\
TG & Giá trị ngưỡng dòng chảy ngầm & 0,6 \\
CKBF $(\operatorname{tg})$ & Hệ số thời gian dòng chảy ngầm & 3500 \\
\hline
\end{tabular}

Kiểm định mô hình: Sau khi có bộ thông số mô hình ta tiến hành kiểm định mô hình. Việc kiểm định mô hình là bước rất cần thiết nhằm mục đích đánh giá lại xem bộ thông số đã xác định ở trên có đảm bảo sử dụng được trong thực tế hay không trước khi sử dụng chúng để tính toán áp dụng. Thời gian kiểm định gồm 3 giai đoạn: giai đoạn 1 từ 2011-2015, giai đoạn 2 từ 2007-2010 và năm lũ (năm 2000). Kết quả hiệu chỉnh, kiểm định mô hình như sau:

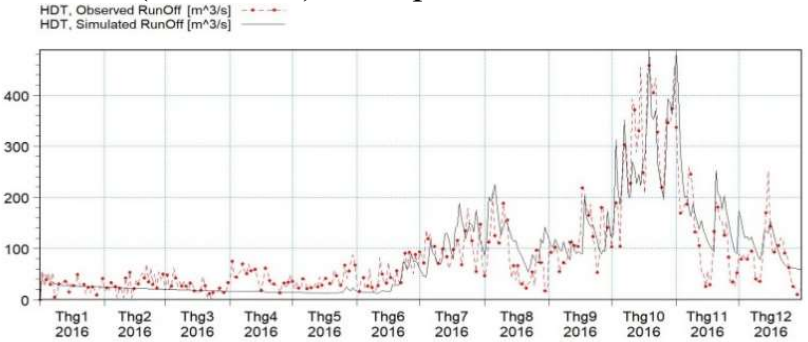

Hình 9. Hiệu chỉnh lưu lượng về hồ năm 2016 .
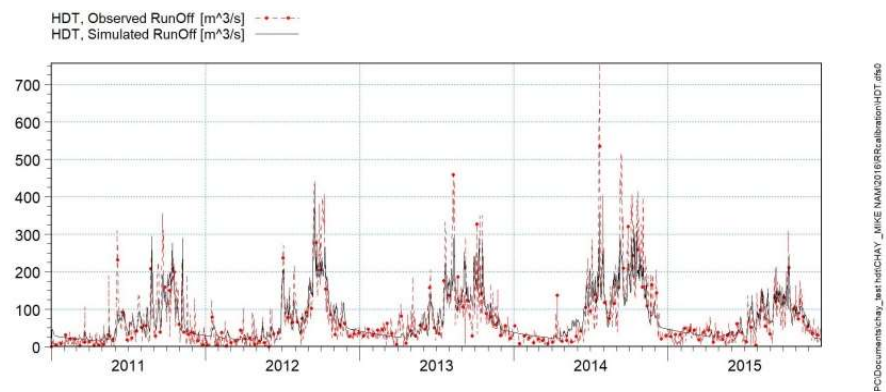

Hình 10. Kiểm định lưu lượng về hồ giai đoạn 2011-2015.
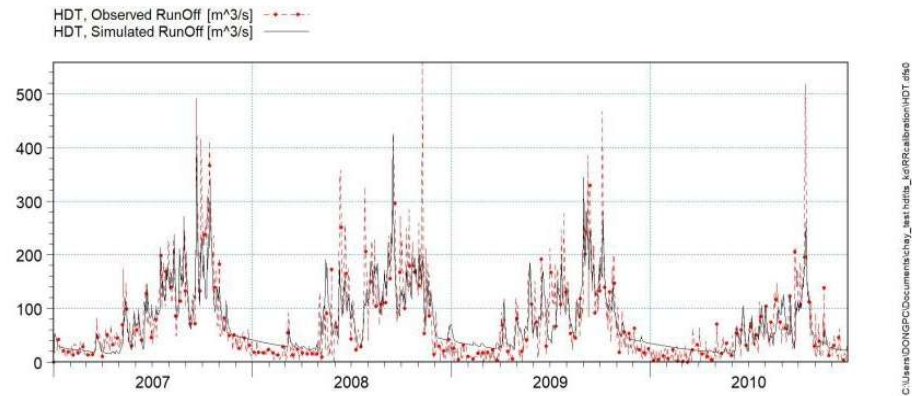

Hình 11. Kiểm định lưu lượng về hồ giai đoạn năm 2007-2010. 


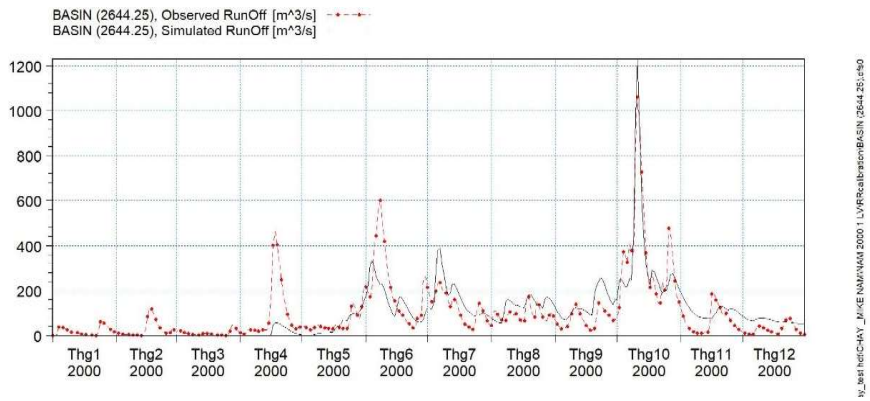

Hình 12. Kiểm định lưu lượng về hồ năm lũ 2000.

Để có thể đánh giá độ chính xác của mô hình, sử dụng hệ số đánh giá các quá trình thủy động lực Nash-Sutcliffe:

Bảng 7. Thống kê kết quả hiệu chỉnh kiểm định mô hình Mike Nam.

\begin{tabular}{lcccccc}
\hline \multirow{2}{*}{ Lưu vực } & \multirow{2}{*}{ Hệ số } & Hiệu chỉnh & \multicolumn{3}{c}{ Kiểm định } & Đơn vị \\
\cline { 3 - 6 } & & Năm 2016 & Giai đoạn 1 & Giai đoạn 2 & Giai đoạn 3 & Năm 2000 \\
\hline Hồ Dầu & Nash & 0,752 & 0,657 & 0,715 & $2007-2010$ & 0,669 \\
Tiếng & WBL & $-1,1$ & $-0,70$ & $-0,30$ & $-2,2$ & $\%$ \\
\hline
\end{tabular}

Độ hữu hiệu của mô hình theo hệ số Nash đạt trên 0,65 . Mô hình được đánh giá vào mức độ khá, đường quá trình lưu lượng tính từ mưa bằng mô hình NAM khá phù hợp với đường quá trình dòng chảy thực đo. Từ đấy, nghiên cứu có thể sử dụng bộ thông số này để mô phỏng chế độ dòng chảy trên lưu vực hồ Dầu Tiếng. Sử dụng phần mềm FFC2008, phân bổ và tổng hợp mưa thiết kế các trạm theo hệ số tính từ diện tích đa giác Thiessen và đưa vào làm số liệu đầu vào cho mô hình NAM đã hiệu chỉnh kiểm định, thu được dòng chảy năm thiết kế ứng với các tần suất khác nhau. Chọn năm trung bình nước làm năm hiện trạng để tính toán, mô phỏng cá kịch bản BĐKH. Kết quả mô phỏng chế độ dòng chảy đến hồ Dầu Tiếng theo năm hiện trạng và theo các kịch bản biến đổi khí hậu được thể hiện ở hình 14.

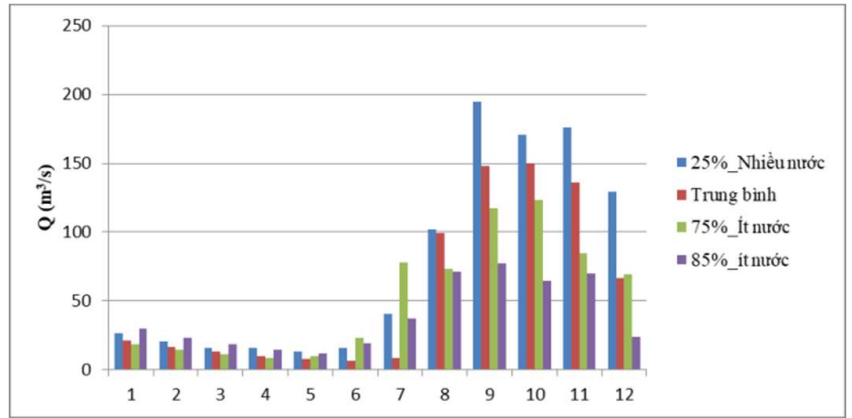

Hình 13. Phân bố dòng chảy đến hồ chứa theo năm điển hình trung bình nước, nhiều nước $(25 \%)$, ít nước $(75 \%, 85 \%)$.
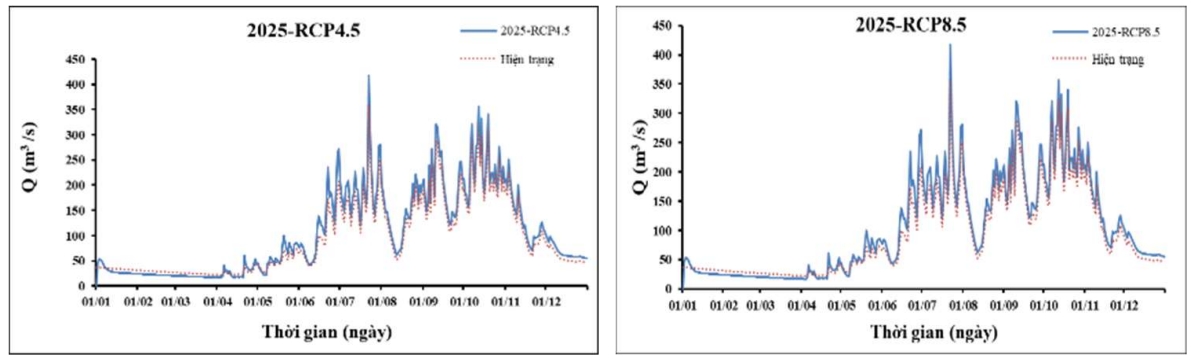

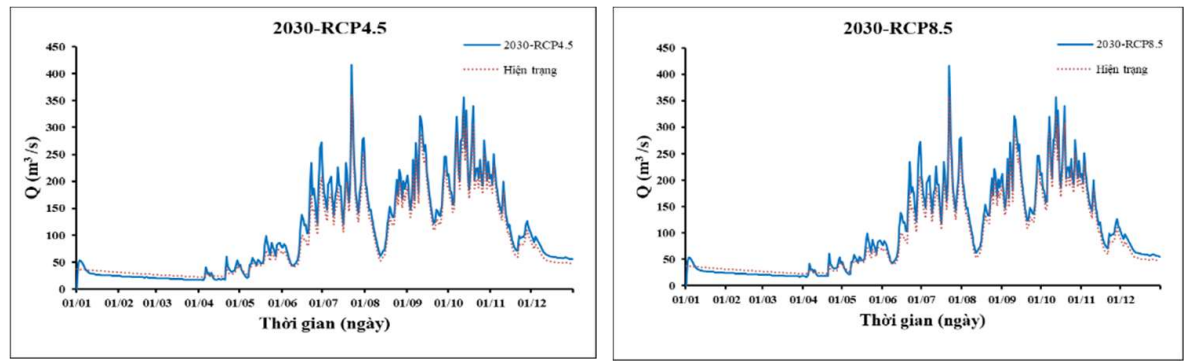

Hình 14. Kết quả lưu lượng về hồ Dầu Tiếng theo các kịch bản BĐKH.

Qua biểu đồ so sánh có thể thấy dòng chảy lưu vực Hồ Dầu Tiếng thay đổi rõ rệt khi chịu tác động của biến đổi khí hậu. Lưu lượng cao nhất vào khoảng tháng VII đến tháng XI. Đối với năm hiện trạng, lưu lượng đến hồ trung bình năm $\mathrm{Q}_{\mathrm{TB}}=94,2 \mathrm{~m}^{3} / \mathrm{s}$, trong đó lưu lượng đến hồ lớn nhất vào tháng VII đạt $359,59 \mathrm{~m}^{3} / \mathrm{s}$, lưu lượng nước đến hồ vào mùa khô tương đối ít $43,16 \mathrm{~m}^{3} / \mathrm{s}$ đến năm 2030 , lưu lượng đến hồ trung bình năm khoảng $104,7 \mathrm{~m}^{3} / \mathrm{s}$ trong đó lưu lượng đến hồ lớn nhất đạt $417,83 \mathrm{~m}^{3} / \mathrm{s}$, cho thấy chế độ dòng chảy tại lưu vực có sự thay đổi tương đối lớn nhất là trong mùa mưa, mùa khô lưu lượng về hồ không có sự thay đồi đáng kể. Nhận thấy lượng mưa lớn dẫn đến lưu lượng tăng vào các khoảng thời gian mùa mưa, gây lượng nước ở Hồ Dầu Tiếng tăng cao, có nguy cơ hồ phải tăng lưu lượng xả lũ gây ảnh hưởng đến các khu vực lân cận. Do vậy việc vận hành hồ chứa rất quan trọng trong thời kì biến đồi khí hậu hiện nay.

\section{3. Úng dụng mô hình thủy văn lưu vưc tính toán điều tiết hồ}

\subsubsection{Hiệu chỉnh kiểm định mô hình}

Mô hình thủy văn lưu vực được lựa chọn để tính toán là MIKE HYDRO Basin nhằm xác định các giá trị lưu lượng về và lưu lượng xả tại các nút hồ theo các phương án điều tiết của hệ thống hồ chứa thủy lợi Dầu Tiếng.

Hiệu chỉnh mô hình: Để đánh giá khả năng mô phỏng của mô hình trong vận hành điều tiết, thực hiện mô phỏng quá trình mực nước và dung tích hồ theo chuỗi thời gian từ 2012 đến 2015 để hiệu chỉnh mô hình (Hình 15).

Kiểm định mô hình: Sử dụng số liệu năm lũ đặc biệt lớn (năm 2000) được mô phỏng để xem xét khả năng mô phỏng vận hành xả theo thực tế của mô hình (Hình 16). Kết quả hiệu chỉnh, kiểm định mô hình được thể hiện trong hình 15.

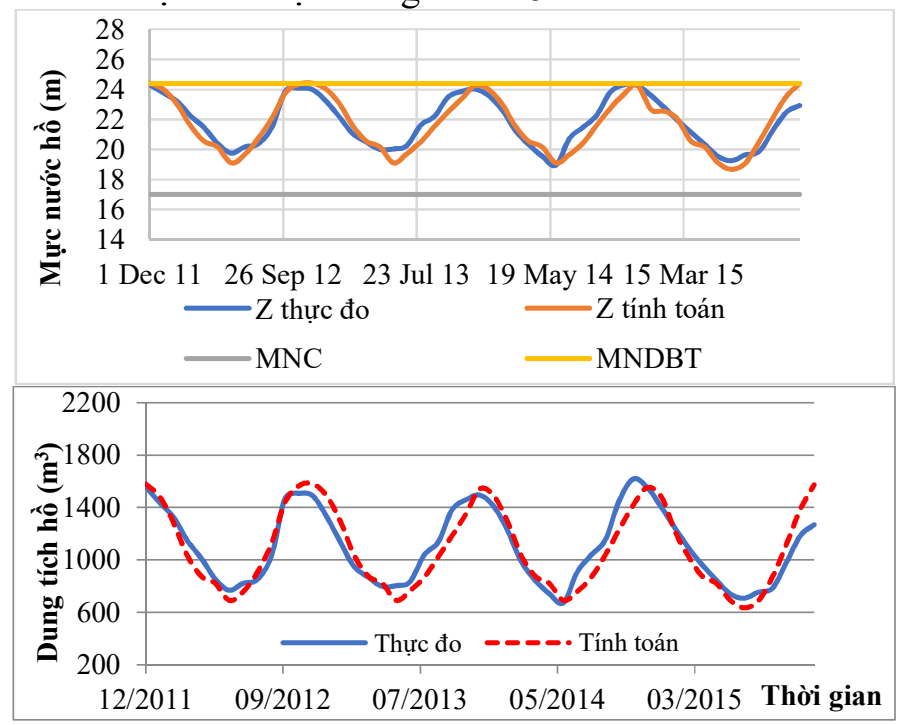

Hình 15. Quá trình mực nước hồ, dung tích hồ giữa thực đo và tính toán từ năm 2012-2015. 


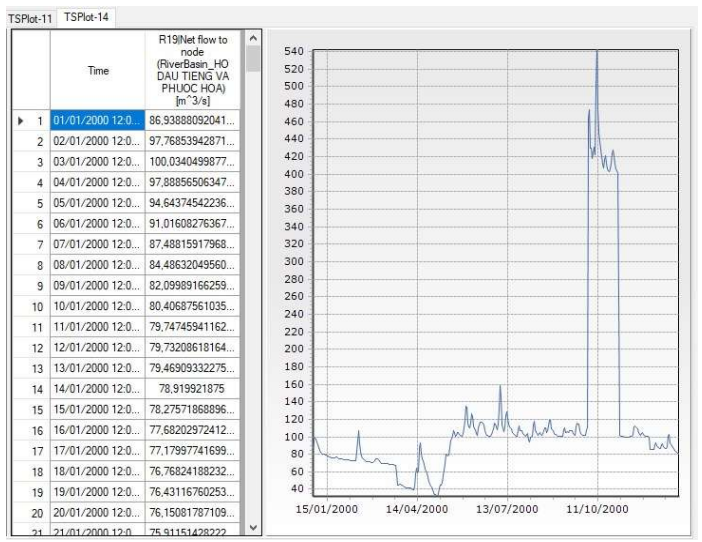

Hình 16. Đường quá trình lưu lượng xả của hồ Dầu Tiếng năm 2000.

Đường dung tích mô phỏng hầu hết năm nằm trong phạm vi hoạt động của hồ (biểu đồ điều phối theo phê duyệt), nằm dưới mực nước phòng lũ và nằm trên đường hạn chế cấp nước. Tháng 10 năm 2000 với lưu lượng đến hồ thực đo là $350 \mathrm{~m}^{3} / \mathrm{s}$, sau khi vận hành hồ theo đúng quy trình vận hành dễ dàng nhận thấy rằng lưu lượng xả max đạt được là $542 \mathrm{~m}^{3} / \mathrm{s}$ gần với số liệu thực đo xả qua tràn xả sâu năm 2000 là gần $600 \mathrm{~m}^{3} / \mathrm{s}$.

Lưu lượng lũ xả đo thực tế làm đại diện cho một ngày trong khi lưu lượng xả mô phỏng được tính theo thời đoạn trung bình ngày. Kết quả mô phỏng cho năm lũ có thể chấp nhận được. Mô hình MIKE HYDRO Basin hoàn toàn phù hợp để mô phỏng điều tiết cho hồ Dầu Tiếng kịch bản tính toán dòng chảy đến hồ khác nhau.

3.3.2. Đánh giá lưu lượng về và lưu lượng xả theo hiện trạng và các trường hợp vận hành

Khả năng cắt giảm lũ cho hạ du các công trình hồ chứa thượng nguồn phụ thuộc rất nhiều vào mực nước hồ khi lũ đến (mực nước đón lũ). Trên cơ sở mực nước đón lũ và các thông số cơ bản của hồ Dầu Tiếng tiến hành điều tiết lũ.

Bảng 8 trình bày kết quả tóm tắt điều tiết lũ, bao gồm mực nước điều tiết $\left(\mathrm{Z}_{\mathrm{tl}}\right)$, mực nước trong hồ lớn nhất $\left(\mathrm{Z}_{\max }\right)$, lưu lượng lũ đến $\left(\mathrm{Q}_{\max }\right)$, lưu lượng xả qua tràn $\left(\mathrm{q}_{\max }\right)$, chênh lệch mực nước lớn nhất trong hồ với cao trình đỉnh đập $\left(\mathrm{Z}_{Ð \oplus)}\right)$ Ta có: $\mathrm{Z}_{Ð \oplus}=\mathrm{Z}_{\mathrm{max}}-\mathrm{C}_{\mathrm{T}}(\mathrm{CaO}$ trình đỉnh đập).

Bảng 8. Tóm tắt kết quả tính toán điều tiết lũ.

\begin{tabular}{|c|c|c|c|c|c|c|}
\hline \multirow{2}{*}{ STT } & \multirow{2}{*}{ Kịch bản } & \multicolumn{5}{|c|}{ Kết quả điều tiết lũ } \\
\hline & & $\mathrm{Z}_{\mathrm{tl}}(\mathrm{m})$ & $\mathbf{Z}_{\max }(\mathbf{m})$ & $\mathbf{Q}_{\max }\left(\mathrm{m}^{3} / \mathbf{s}\right)$ & $q_{\max }\left(\mathrm{m}^{3} / \mathrm{s}\right)$ & $Z_{\oplus \oplus}(m)$ \\
\hline \multirow{2}{*}{1} & \multirow{2}{*}{ Hiện trạng } & 23,3 & \multirow{2}{*}{25,1} & \multirow{2}{*}{359,59} & 174,53 & $-2,9$ \\
\hline & & 24,4 & & & 177,56 & $-2,9$ \\
\hline \multirow{2}{*}{2} & \multirow{2}{*}{$2025 \mathrm{RCP} 4,5$} & 23,3 & \multirow{2}{*}{25,1} & \multirow{2}{*}{417,08} & 182,62 & $-2,9$ \\
\hline & & 24,4 & & & 185,28 & $-2,9$ \\
\hline \multirow{2}{*}{3} & \multirow{2}{*}{$2025 \mathrm{RCP} 8,5$} & 23,3 & \multirow{2}{*}{25,1} & \multirow{2}{*}{417,38} & 183,11 & $-2,9$ \\
\hline & & 24,4 & & & 186,34 & $-2,9$ \\
\hline \multirow{2}{*}{4} & \multirow{2}{*}{$2030 \mathrm{RCP} 4,5$} & 23,3 & \multirow{2}{*}{25,1} & \multirow{2}{*}{417,72} & 183,32 & $-2,9$ \\
\hline & & 24,4 & & & 186,61 & $-2,9$ \\
\hline \multirow{2}{*}{5} & \multirow{2}{*}{$2030 \mathrm{RCP} 8,5$} & 23,3 & \multirow{2}{*}{25,1} & \multirow{2}{*}{417,83} & 184,4 & $-2,9$ \\
\hline & & 24,4 & & & 187,61 & $-2,9$ \\
\hline
\end{tabular}




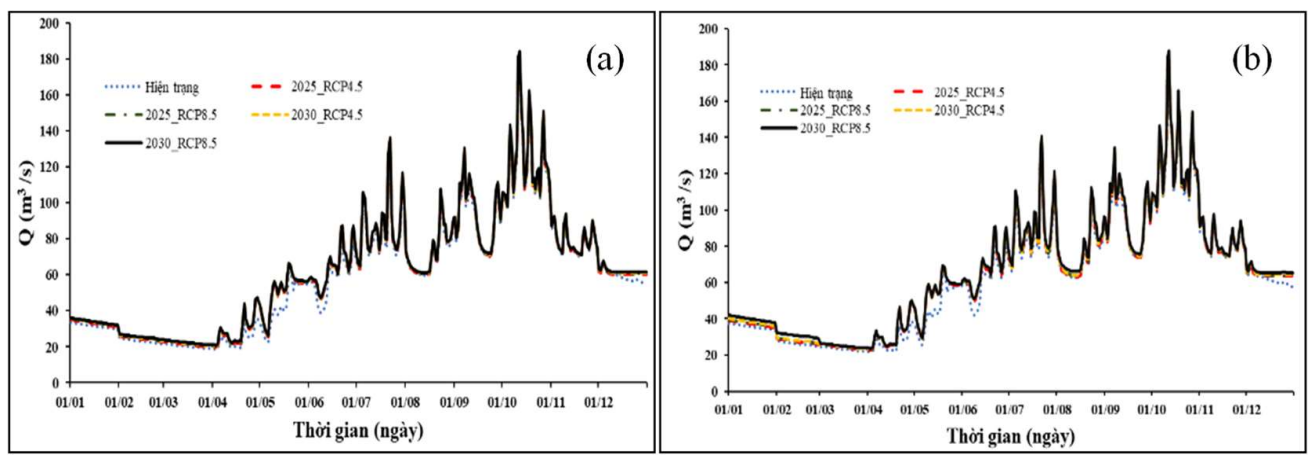

Hình 17. Lưu lượng xả hồ Dầu Tiếng theo hiện trạng và $B Đ K H$ cao trình $23,3 \mathrm{~m}$ (bên trái) và $24,4 \mathrm{~m}$ (bên phải).

Cao trình mực nước hồ trong suốt quá trình vận hành điều tiết vẫn duy trì ở mức dưới mực nước dâng bình thường. Các trường hợp tính toán đối với hai mực nước đón lũ là $23,3 \mathrm{~m}$ (Hình 17a) và $24,4 \mathrm{~m}$ (Hình $17 \mathrm{~b}$ ) với các kịch bản $\mathrm{BĐKH} \mathrm{khác} \mathrm{nhau,} \mathrm{chưa} \mathrm{có} \mathrm{trường} \mathrm{hợp} \mathrm{nào}$ lưu lượng xả vượt quá khả năng xả lũ cửa tràn (xả nuớc thường xuyên, liên tục về hạ du sông Sài Gòn đảm bảo lưu lượng không nhỏ hơn $36 \mathrm{~m}^{3} / \mathrm{s}$ và đảm bảo lưu lượng xả về hạ du không vượt quá $200 \mathrm{~m}^{3} / \mathrm{s}$ ), kết quả điều tiết phù hợp với quy trình vận hành hồ Dầu Tiếng.

Vào mùa khô: Lưu lượng xả xuống hạ lưu sông Sài Gòn nhằm duy trì dòng chảy môi trường xả đẩy mặn cho hạ du. Tuy nhiên, trong các tháng này, lượng nước vào hồ khá thấp, không đủ cấp nước phục vụ nhu cầu thủy lợi như nhiệm vụ để ra, do đó, hồ Phước Hòa đã cấp thêm một lượng nước $\mathrm{Q}=50 \mathrm{~m} / \mathrm{s}$ cho hồ Dầu Tiếng bằng một kênh nhân tạo nối từ sau Hồ Phước Hòa đến trước Hồ Dầu Tiếng.

Vào mùa mưa: Các tháng đầu mùa mưa, lưu lượng tích lại trong hồ phục vụ cho tưới tiêu nông nghiệp và cấp nước qua 3 cống số 1,2 và 3 , kênh đào Tân Hưng và hệt hống dẫn nước tưới tiêu Kênh Đông và Kênh Tây. Theo Hình 17, hồ Dầu Tiếng điều tiết giảm lũ hiệu quả, bên cạnh đó, mực nước hồ đảm bảo an toàn với cao trình cao hơn mực nước chết $(+17 \mathrm{~m})$ và không vượt quá mực nước lũ thiết kế $(+25,1 \mathrm{~m})$.

\section{Kết luận}

Kết quả nghiên cứu cho thấy, ứng dụng mô hình thủy văn, thủy văn lưu vực MIKE NAM và MIKE HYDRO Basin cho thấy việc mô phỏng chế độ dòng chảy đến hồ khá tốt. Sau khi tiến hành hiệu chỉnh kiểm định mô hình, hệ số Nash lưu vực hồ Dầu Tiếng đều trên 0,65 (đạt loại khá), mức độ sai số khá thấp về sai số tổng lượng. Khi tính toán dòng chảy đến hồ Dầu Tiếng theo các năm điển hình (năm nhiều nước, năm ít nước và năm trung bình nước) cũng cho thấy sự biến thiên rõ rệt dòng chảy theo mùa. Chênh lệch giữa năm nhiều nước và ít nước cũng rất đáng kể, năm nhiều nước có dòng chảy trung bình năm đến hơn $170 \mathrm{~m}^{3} / \mathrm{s}$ trong khi năm ít lại chỉ có khoảng $36 \mathrm{~m}^{3} / \mathrm{s}$. Ngoài ra, việc thay đổi lớp phủ thực vật cũng tác động rất lớn đến chế độ dòng chảy tại lưu vực. Qua quá trình mô phỏng nhận thấy các kịch bản làm thay đổi dòng chảy trong năm là tương đối cao, tương lai dòng chảy sẽ còn thay đổi và diễn biến phức tạp thêm nữa. Những kịch bản biến đổi khí hậu này tạo tiền đề để xây dựng các công trình phục vụ nhu cầu và lợi ích cho đời sống con người, do vậy việc vận hành hồ chứa rất quan trọng trong thời kì biến đổi khi hậu hiện nay.

Khi có chuyển nước từ Phước Hòa sang, dòng chảy mùa kiệt tăng lên rõ rệt (gấp đôi) có tháng còn nhiều hơn dòng chảy trung bình tháng của Dầu Tiếng khi chưa có Phước Hòa. Ngoài ra, dựa trên quy trình vận hành hồ, điều tiết hồ Dầu Tiếng vận hành xả theo các kịch bản $\mathrm{BĐKH.} \mathrm{Kết} \mathrm{quả} \mathrm{ở} \mathrm{giai} \mathrm{đoạn} \mathrm{hiện} \mathrm{trạng} \mathrm{và} \mathrm{theo} \mathrm{các} \mathrm{kịch} \mathrm{bản} \mathrm{BĐKH}$, hình thức điều tiết của hồ là nhiều năm, hồ xả nước thường xuyên, liên tục về hạ du sông Sài Gòn đảm bảo lưu lượng không nhỏ hơn $36 \mathrm{~m}$ ³/s và đảm bảo lưu lượng xả về hạ du không vượt quá $200 \mathrm{~m}^{3} / \mathrm{s}$, 
chưa có trường hợp nào xả vượt quá khả năng xả lũ của cửa tràn. (phù hợp với quy trình vận hành hồ Dầu Tiếng)

Qua các kịch bản đã phân tích, mỗi trường hợp cụ thể sẽ có giải pháp vận hành hồ phù hợp nhằm giải quyết mâu thuẫn giữa đảm bảo an toàn công trình đầu mối và hạ du hồ Dầu Tiểng, ngập lụt TP. HCM và các vùng lân cận trong bối cảnh biến đổi khí hậu. Để kiểm soát lưu lượng xả lũ qua hồ Dầu Tiếng xuống hạ du cần có các phương án vận hành hồ phù hợp và hiệu quả. Do đó, trong thời gian tới cần thu thập, phân tích, dự báo mưa qua các mô hình khác nhau nhằm nâng cao công tác dự báo dòng chảy đến hồ, làm cơ sở để các nhà quản lý chủ động điều tiết lũ.

Đóng góp cho nghiên cứu: Xây dựng ý tưởng nghiên cứu: T.T.H.; Lựa chọn phương pháp nghiên cứu: T.T.H., P.A.B.; Xử lý số liệu: T.T.H., H.C.T.; Thu thập, phân tích, xử lý số liệu: H.C.T., P.A.B.; Viết bản thảo bài báo: T.T.H., P.A.B., H.C.T.; Chỉnh sửa bài báo: T.T.H.

Lời cảm ơn: Nghiên cứu này được thực hiện dưới sự hỗ trợ của đề tài nghiên cứu khoa học cấp cơ sở "Ứng dụng mô hình MIKE HYDRO tính toán lưu lượng về hồ Dầu Tiếng phục vụ công tác vận hành hồ chứa dưới tác động của biến đổi khí hậu".

Lời cam đoan: Tập thể tác giả cam đoan bài báo này là công trình nghiên cứu của tập thể tác giả, chưa được công bố ở đâu, không được sao chép từ những nghiên cứu trước đây; không có sự tranh chấp lợi ích trong nhóm tác giả.

\section{Tài liệu tham khảo}

1. Mahmood, R.; Jia, S. Analysis of causes of decreasing inflow to the Lake Chad due to climate variability and human activities. Hydrol. Earth Syst. Sci. Discuss. 2018, $1-$ 42. https://doi.org/10.5194/hess-2018-139.

2. Hafezparast, M.; Araghinejad, S.; Fatemi, S.E.; Bressers, H.A. Conceptual RainfallRunoff Model Using the Auto Calibrated NAM Models in the Sarisoo River. Hydrol. Curr. Res. 2013, 4, 1-6.

3. Santor, R.M.B.; Fernandes, L.F.S.; Cortes, R.M.V.; Pacheco, F.A.L. Development of a Hydrologic and Water Allocation Model to Assess Water Availability in the Sabor River Basin (Portugal). Int. J. Environ. Res. Public Health 2019, 16, 2419.

4. Yang, Y.; Disse, M.; Ruide, Y.; Guoan, Y.; Lingxiao, S.; Huttner, P.; Rumbaur, C. Large-Scale Hydrological Modeling and Decision-Making for Agricultural Water Consumption and Allocation in the Main Stem Tarim River, China. Water 2015, 7, 2821-2839. https://doi.org/10.3390/w7062821.

5. IPCC. Climate Change: The Physical Science Basis. Contribution of Working Group I to the Fourth Assessment Report of the Intergovernmental Panel on Climate Change, 2007.

6. IPCC. Climate Change: The Physical Science Basis. Contribution of Working Group I to the Fifth Assessment Report of the Intergovernmental Panel on Climate Change, 2013.

7. Bộ Tài nguyên Môi trường. Kịch bản Biến đổi khí hậu, nước biển dâng cho Việt Nam, 2012.

8. Bộ Tài nguyên Môi trường. Kịch bản Biến đổi khí hậu, nước biển dâng cho Việt Nam, 2016.

9. Anh, T.N. Đánh giá khả năng cấp nước hồ Dầu Tiếng theo các kịch bản thiếu hụt bằng mô hình HEC-RESSIM. Khoa học Kỹ thuật Thủy lợi và Môi trường, 2016. 
10. Duong, N.B.; San, D.C.; Nghia, P.D. Phân tích mối quan hệ giữa lượng nước xả cuống sông Sài Gòn từ hồ Dầu Tiếng với hiệu quả đẩy mặn. Viện Khoa học Thủy lợi Miền Nam, 2009.

11. San, D.C.; Lanh, N.V.; Thanh, L.N. Dự báo mưa trên lưu vực hồ Dầu Tiếng từ tài liệu dự báo thời tiết toàn cầu phục vụ dự báo dòng chảy lũ đến và điều tiết hồ chứa trong mùa mưa lũ, 2019.

12. Khiêm, M.V. Nghiên cứu khả năng đáp ứng của hệ thống thoát nước trên địa bàn TP. HCM trong điều kiện biến đổi khí hậu. Báo cáo tổng kết Đề tài cấp Sở Khoa học và Công nghệ TP. HCM, 2019.

13. DHI. MIKEHydro_UserGuide.pdf. 2014.

14. DHI. MIKEZero.pdf. 2014.

15. Giáo trình thủy lực môi trường. Bộ môn cơ lưu chất - Khoa kỹ thuật xây dựng, Đại học Bách Khoa, Đại học Quốc Gia TP.HCM. NXB Đại học Quốc gia TP. HCM, 2005.

16. Wayne, G. The beginner's guide to Representative Concentration Pathways. Skeptical Science 2013, pp. 25.

17. Viện Khoa học Khí tượng Thủy văn và Biến đổi khí hậu. Tư vấn kỹ thuật về dữ liệu và phân tích khí hậu hiện tại và tương lai phục vụ công tác quản lý nguồn nước tại tỉnh Hà Tĩnh. Báo cáo tổng kết dự án, 2016.

18. Amengual, A.; Homar, V.; Romero, R.; Alonso, S.; Ramis, C. A Statistical Adjustment of Regional Climate Model Outputs to Local Scales: Application to Platja de Palma, Spain. J. Climate 2012, 25, 939-957. https://doi.org/10.1175/JCLID-10-05024.1

19. Hiệp, N.V. Nghiên cứu luận cứ khoa học cập nhật kịch bản biến đổi khí hậu và nước biển dâng cho Việt Nam. Báo cáo tổng kết đề tài cấp nhà nước, Mã số: BĐKH.43/16-20, 2013.

20. Quyết định số 2581/QĐ-BNN-XD của Bộ Nông nghiệp và PTNN về phê duyệt điều chỉnh dự án Thủy lợi Phước Hòa tỉnh Bình Dương, Bình Phước, 2008.

\section{Assessment of the change in discharge to Dau Tieng reservoir according to the climate change scenarios}

\section{Tran Tuan Hoang ${ }^{*}$, Pham Anh Binh ${ }^{1}$, Nguyen Phuong Dong${ }^{1}$, Ho Cong Toan ${ }^{1}$, Nguyen Thao Hien ${ }^{1}$, Chau Thanh Hai ${ }^{1}$}

1 Sub-Institue of Hydrometeorology and Climate Change; hoangkttv@gmail.com; binhpi1909@gmail.com; donghai930t110@gmail.com; hocongtoanhdh@gmail.com; nthien2710@gmail.com; haisihymete@gmail.com

Abstract: In this study, MIKE NAM and MIKE HYDRO models have been applied to simulate the flow to Dau Tieng reservoir, then calculate the reservoir regulation according to the climate change scenarios. Calculation results of water sources to the reservoir demonstrate clear variations in flow according to seasons. The different between a year with lots of water and a year with little water is also very significant. A year with much of water, the average annual flow of more than $170 \mathrm{~m}^{3} / \mathrm{s}$, meanwhile, a year with a little water about $36 \mathrm{~m}^{3} / \mathrm{s}$. The MIKE HYDRO model has illustrated operational efficiency through the test of 
water level and reservoir capacity in 4 years (2012-2015) and flood regulation for the major flood in 2000. The study results based on the reservoir operation process, the reservoir has been regulated corresponding to cases where the flood volume is less than the normal rising water level or the flood-receiving water level of the reservoir. The research results prove that the model is capable of effective application, which is the basis for managers, planning and supporting to operate the Dau Tieng reservoir properly as well as ensure safety for the downstream area of the Saigon River.

Keyword: Reservoir regulation; Reservoir operation; Dau Tieng reservoir; Climate change. 